\title{
RESEARCH
}

Open Access

\section{Trajectories of objectively measured physical activity and childhood overweight: longitudinal analysis of the IDEFICS/I.Family cohort}

Ole Sprengeler ${ }^{1 \dagger}$, Hermann Pohlabeln ${ }^{2 *+}$ D , Karin Bammann ${ }^{2,3}$, Christoph Buck $^{2}$, Fabio Lauria ${ }^{4}$, Vera Verbestel ${ }^{5}$, Gabriele Eiben ${ }^{6}$, Kenn Konstabel ${ }^{7,8,9}$, Dénes Molnár ${ }^{10}$, Luis A. Moreno ${ }^{11,12,13,14}$, Yannis Pitsiladis ${ }^{15}$, Angie Page ${ }^{16,17}$, Lucia Reisch $^{18}$, Michael Tornaritis ${ }^{19}$ and Wolfgang Ahrens ${ }^{1,20}$

\begin{abstract}
Background: Since only few longitudinal studies with appropriate study designs investigated the relationship between objectively measured physical activity (PA) and overweight, the degree PA can prevent excess weight gain in children, remains unclear. Moreover, evidence is limited on how childhood overweight determines PA during childhood. Therefore, we analyzed longitudinal trajectories of objectively measured PA and their bi-directional association with weight trajectories of children at 2- and 6-year follow-ups.

Methods: Longitudinal data of three subsequent measurements from the IDEFICS/I.Family cohort study were used to analyze the bi-directional association between moderate-to-vigorous PA (MVPA) and weight status by means of multilevel regression models. Analyses comprised 3393 (2-year follow-up) and 1899 (6-year follow-up) children aged 2-15.9 years from eight European countries with valid accelerometer data and body mass index (BMI) measurements. For categorized analyses, children's weight status was categorized as normal weight or overweight (cutoff: 90th percentile of BMI) and children's PA as (in-) sufficiently active (cutoffs: 30, 45 and 60 min of MVPA per day).

Results: Children engaging in at least 60 min MVPA daily at baseline and follow-ups had a lower odds of becoming overweight (odds ratio [OR] at 2-year follow-up: 0.546, 95\% Cl: 0.378, 0.789 and 6-year follow-up: 0.393, 95\% Cl: $0.242,0.638)$, compared to less active children. Similar associations were found for 45 min MVPA daily. On the other side, children who became overweight had the lowest odds to achieve 45 or 60 min MVPA daily (ORs: 0.459 to 0.634), compared to normal weight children.
\end{abstract}

\footnotetext{
* Correspondence: pohlabeln@leibniz-bips.de

${ }^{\dagger}$ Ole Sprengeler and Hermann Pohlabeln are shared first authorship ${ }^{2}$ Department of Biometry and Data Management, Leibniz Institute for Prevention Research and Epidemiology - BIPS, Achterstraße 30, D-28359 Bremen, Germany

Full list of author information is available at the end of the article
}

(c) The Author(s). 2021 Open Access This article is licensed under a Creative Commons Attribution 4.0 International License, which permits use, sharing, adaptation, distribution and reproduction in any medium or format, as long as you give appropriate credit to the original author(s) and the source, provide a link to the Creative Commons licence, and indicate if changes were made. The images or other third party material in this article are included in the article's Creative Commons licence, unless indicated otherwise in a credit line to the material. If material is not included in the article's Creative Commons licence and your intended use is not permitted by statutory regulation or exceeds the permitted use, you will need to obtain permission directly from the copyright holder. To view a copy of this licence, visit http://creativecommons.org/licenses/by/4.0/. The Creative Commons Public Domain Dedication waiver (http://creativecommons.org/publicdomain/zero/1.0/) applies to the data made available in this article, unless otherwise stated in a credit line to the data. 
Conclusions: Bi-directional associations between MVPA and weight status were observed. In summary, at least 60 min MVPA are still recommended for the prevention of childhood overweight. To prevent excess weight gain, 45 min MVPA per day also showed preventive effects.

Keywords: Health-enhancing physical activity, Pediatric overweight, Obesity prevention, Dose-response relationship, Physical activity recommendations

\section{Background}

About $20 \%$ of children and adolescents in developed and developing countries are overweight or obese [1-3]. Although some studies have found no further increase in prevalence in recent years, the proportion of children and adolescents having overweight and obesity has reached a plateau at a high level [1,4]. Childhood obesity and overweight are a major public health problem [2, 4] since cardiometabolic health is adversely affected by excessive fat mass [5, 6]. Furthermore, higher fat mass in childhood increases the risk of having obesity in adolescence and adulthood $[7,8]$. The assumption that sufficient MVPA prevents excessive fat mass has become widely accepted since numerous cross-sectional studies have shown an inverse association between the level of high physical activity (PA) intensities such as moderateto-vigorous PA (MVPA) and the prevalence of overweight and obesity in children [8-12]. Hence, national and international health care institutions recommend MVPA of at least $60 \mathrm{~min}$ per day for children and adolescents and $150 \mathrm{~min}$ of MVPA per week for adults [13, 14] to prevent obesity and other chronic diseases and to maintain metabolic health.

However, causal inferences about the direction of the association between PA and weight status can only be drawn from longitudinal studies using objective measurements of PA and age- and sex-adjusted body weight [15-17]. Up to now, only few longitudinal studies have been conducted with appropriate study designs $[10,15$, 18]. Most of them with only small sample sizes $(N<$ 300 ), either confirming the well-known cross-sectional association between PA and weight status [10] or finding an inverse association between body fat at baseline and MVPA at follow-up [15]. Furthermore, a recent review highlighted that "dose-response evidence" of PA for the prevention of childhood overweight and obesity is still lacking [19] and the recommended MVPA cutoff (60 min MVPA per day) supposed to prevent metabolic diseases such as obesity need to be scrutinized. This issue was also raised recently by Warburton and Bredin (2018) highlighting that dose-response-relationships in health studies are not always translated correctly. The authors pointed out that while some of the recommended health-improving doses of PA such as the MVPA level of 60 min per day may prevent chronic diseases, smaller amounts of PA may also improve several health parameters to an appreciable extent [20]. Our study offers the unique opportunity to investigate the bidirectional association between objectively measured MVPA and weight status in a large international sample (the IDEFICS/I.Family cohort), and moreover, to exploratively investigate whether MVPA less than the generally recommended $60 \mathrm{~min}$ per day (by arbitrarily taking 30 and $45 \mathrm{~min}$ per day as cutoff for sufficient MVPA) may already have a positive effect on weight status of children.

\section{Methods \\ Study population}

More than 16,000 participants aged 2-9.9 years were initially recruited at baseline (T0: 2007-2008) across eight European countries (Belgium, Cyprus, Estonia, Germany, Hungary, Italy, Spain, and Sweden) in the IDEFICS study. This study is currently the largest prospective study in European children investigating health-related behavior and metabolic outcomes in children and their families. Comprehensive examinations included physical examinations, blood samples, assessment of dietary and PA patterns at baseline, the first follow-up (T1: 20092010) and the second follow-up (T3: 2013-2014). It needs to be acknowledged that a further in-between follow-up (T2) was conducted as mail survey only and thus, was not considered in the present study. Parents gave written informed consent. Additionally, oral consent was obtained from children just before the examination. Ethical approval was obtained from the responsible authority of each participating study center. Further details of the study design and examination protocol have been reported elsewhere [21, 22].

\section{PA measurement}

Intensities of PA were assessed by uniaxial accelerometry using Actigraph models (GT1M, GT3X and ActiTrainer; Actigraph, Pensacola, Florida, USA). The sample interval was set to an epoch of $15 \mathrm{~s}$. During the first wave in Italy, an epoch length of $60 \mathrm{~s}$ was selected in most cases. We accounted for this by using the correction factor recommended by Colley and colleagues [23]. The accelerometers were attached to the right hip with a measuring tape. Each child was verbally instructed to wear the device for at least three consecutive days during waking hours, except when bathing or swimming. Additionally, 
all parents received written instructions on accelerometer usage and on how to record non-wear time of the device in diaries provided by the study personnel. About $13 \%$ of all children took off the device at least once during sports or water-based activities and recorded this in the non-wear diaries. If the recorded activities qualified as MVPA according to the Ainsworth Compendium for Youth [24], we imputed the recorded duration as MVPA as recently recommended [25], corrected by a factor of 0.5 for all different types of sports activities (physical education, training and competitions). Evenson cutoffpoints [26] typically applied for school-aged children were used to categorize MVPA for all children (schoolaged, kindergarten/pre-school children). Non-wear time was defined as at least $90 \mathrm{~min}$ of consecutive zeros and was removed from the data, as recommended [27]. To be included in the analysis, a minimum of six hours wear-time per day for at least 3 days (at least two weekdays and one weekend day) was required. Children with at least an average of 60 min MVPA per valid day were categorized as sufficiently active according to the WHO recommendations [13]. We consciously decided to use the absolute minutes of daily MVPA rather than proportions (\%/day), since PA guidelines are also expressed in minutes per day.

\section{Anthropometric measurements}

All physical examinations were conducted by trained study personnel according to the IDEFICS/I.Family study protocol in all three waves (T0/T1/T3). Waist circumference as well as body height and weight were measured at the local study centers. Details of the anthropometric measurements have been described elsewhere $[22,28]$. Anthropometric values were included as percentiles for waist circumference and BMI, respectively.

\section{Waist circumference}

Waist circumference was measured in a standing position using a measuring tape (Seca 200), precision 0.1 $\mathrm{cm}$, range: $0-150 \mathrm{~cm}$.

\section{Body mass index (BMI)}

To calculate the BMI, body weight $(\mathrm{kg})$ was divided by the square of body height $(\mathrm{m})$. Children wore underwear and a T-shirt for weighing. Weight was measured to the nearest $0.1 \mathrm{~kg}$ using an electronic scale (Tanita BC 240 SMA, Tanita Europe, Sindelfingen, Germany). Height was measured barefoot with a telescopic height measuring instrument (Seca 225 stadiometer, Seca, Birmingham, UK) to the nearest $0.1 \mathrm{~cm}$.

\section{Statistical analyses}

Two different modeling approaches were chosen to examine the bi-directional relationship between PA and weight status. In the first approach, the outcome was modeled as a continuous variable and in the second approach as a dichotomous variable.

- Weight status as outcome:

Weight status of children was modeled continuously by means of BMI percentile based on the International (IOTF) BMI percentile curves updated by Cole \& Lobstein [29]. For the second approach, this continuous variable was dichotomized and children with a BMI above the 90th percentile were considered having overweight or obesity.

- PA as outcome:

PA was modeled continuously as objectively measured average daily minutes of MVPA. For the second approach, this variable was dichotomized at the generally recommended MVPA cutoff, i.e., 60 min per day.

- Weight status / PA as categorized exposures:

When analyzing the potential influence of weight status on PA, weight status was modeled as a dichotomous exposure (as previously described) and when analyzing the possible influence of PA on weight status, PA was also modeled (as previously defined) as a dichotomous exposure. Finally, we combined exposure levels at baseline and follow-up to analyze the association of changes in weight status (between baseline and follow-up) on PA level at follow-up and vice versa, i.e., to analyze the association of changes in PA levels (between baseline and follow-up) on weight status at follow-up.

However, to explore whether even smaller amounts than 60 min daily are efficient to prevent overweight and obesity, we arbitrarily reduced this cutoff to also 45 and $30 \mathrm{~min}$ per day to categorize children as 'sufficiently active' in minutes of MVPA.

Based on these variables and cutoffs, associations between MVPA and weight status were analyzed by means of multilevel linear and logistic regression models (with country as random effect). Each of these approaches allowed to investigate both directions, i.e. the effect of the trajectory of PA (from baseline to follow-up) on weight status at follow-up (adjusted for baseline values) and vice versa. All regression estimates (beta coefficients, odds ratios and $95 \%$ confidence intervals $(95 \% \mathrm{CI})$ ) were determined using the SAS procedures MIXED and GLIMMIX (V9.3; SAS Institute Inc., Cary, North Carolina, USA), additionally adjusted for the duration between baseline wave (T0) and follow-up (T1/T3), age, sex, and socio-economic status (SES), the latter based on the "International Standard Classification of Education (ISCED)" contrasting low (ISCED levels 0-2) and medium (ISCED levels 3-5) parental education against high (ISCED levels 6-8) parental education as a proxy 
for SES [30]. In sensitivity analyses all regression analyses were repeated using the study-specific percentiles of waist circumference (instead of BMI percentiles) according to Nagy and colleagues [31]. Moreover, we evaluated whether observed associations differed for boys and girls or by region (North: Germany, Belgium, Sweden, and Estonia; South: Spain, Italy, Cyprus, and Hungary) within Europe. For the sake of simplicity, we will use the term 'overweight' instead of overweight/ obesity in the following.

\section{Results}

Of 16,229 initially participating children at baseline, PA of more than nine thousand children was measured by accelerometry and valid PA was available in 8429 children (Fig. 1). Amongst those, 3393 children were included for the final analysis of the 2-year follow-up (providing valid PA data at both, T0 and T1). Regarding the analysis of the association between baseline and the 6-year follow-up a total of 1899 children could be included (providing valid PA data at both, T0 and T3).

About $50 \%$ of all children included in the 2-year and 6-year follow-up were male (Table 1). In both followups, Sweden, Belgium and Cyprus provided the lowest and Estonia and Spain the largest number of valid observations. Only a small proportion of the children included had a low parental education (3.4-6.0\%). The average age of all included children ranged between 5.9 and 6.3 years at baseline.

Across all waves, the average wear time of accelerometers was at least eleven hours and the time spent in MVPA per day ranged from 53 to $58 \mathrm{~min}$ in boys and 46 to $48 \mathrm{~min}$ in girls.

\section{Association between MVPA levels and subsequent weight status}

The longitudinal association between MVPA levels on subsequent weight status was analyzed according to different trajectories of MVPA levels (i.e. the change of MVPA levels from baseline to follow-up) as exposure for the change in BMI percentiles at 2-year and 6-year follow-up (reference category: insufficiently active at baseline and follow-up) by varying MVPA cutoffs $(<30$, 45 and 60 min per day, Table 2). At 2-year follow-up, the proportion of children who were categorized as sufficiently active ( $\geq 30,45$ and $60 \mathrm{~min}$ MVPA) at baseline and follow-up, decreased continuously ranging from $75 \%$ for the 30-min MVPA cutoff to $15 \%$ for the $60-\mathrm{min}$ MVPA cutoff. Similarly, 74 and $12 \%$ of the children were found to be sufficiently active for the 30- and 60-min MVPA cutoffs, respectively, at 6-year follow-up.

During the 2-year follow-up, the BMI percentile at follow-up was not significantly affected by different MVPA trajectories. Only children who engaged at least

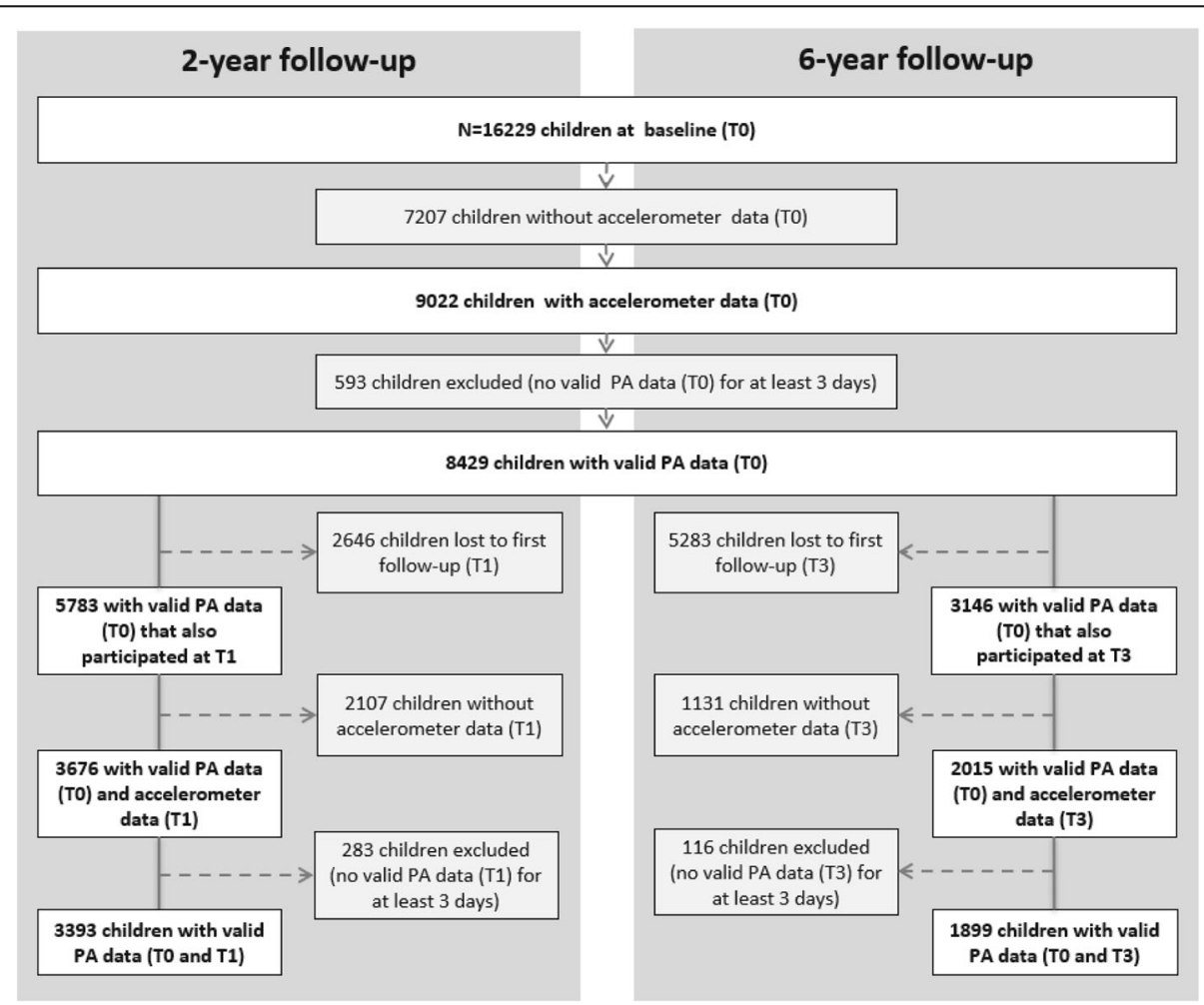

Fig. 1 Study sample and exclusion criteria. Abbreviation: T0, baseline wave; T1, 2-year follow-up; T3, 6-year follow-up; PA, physical activity 
Table 1 Sociodemographic and anthropometric data, physical activity variables for 2-year and 6-year follow-up

\begin{tabular}{|c|c|c|c|c|c|c|c|c|}
\hline \multirow{3}{*}{ Country } & \multicolumn{4}{|c|}{$\begin{array}{l}\text { 2-year follow-up } \\
(N=3393)\end{array}$} & \multicolumn{4}{|c|}{$\begin{array}{l}\text { 6-year follow-up } \\
(N=1899)\end{array}$} \\
\hline & \multicolumn{2}{|l|}{$\begin{array}{l}\text { Boys } \\
(N=1692)\end{array}$} & \multicolumn{2}{|l|}{$\begin{array}{l}\text { Girls } \\
(N=1701)\end{array}$} & \multicolumn{2}{|l|}{$\begin{array}{l}\text { Boys } \\
(N=946)\end{array}$} & \multicolumn{2}{|l|}{$\begin{array}{l}\text { Girls } \\
(N=953)\end{array}$} \\
\hline & $N$ & $\%$ & $N$ & $\%$ & $N$ & $\%$ & $N$ & $\%$ \\
\hline Italy & 178 & 10.5 & 176 & 10.3 & 139 & 14.7 & 112 & 11.8 \\
\hline Estonia & 346 & 20.4 & 372 & 21.9 & 219 & 23.2 & 216 & 22.7 \\
\hline Cyprus & 73 & 4.3 & 73 & 4.3 & 25 & 2.6 & 31 & 3.3 \\
\hline Belgium & 127 & 7.5 & 126 & 7.4 & 32 & 3.4 & 35 & 3.7 \\
\hline Sweden & 77 & 4.6 & 90 & 5.3 & 63 & 6.7 & 57 & 6.0 \\
\hline Germany & 256 & 15.1 & 250 & 14.7 & 120 & 12.7 & 149 & 15.6 \\
\hline Hungary & 161 & 9.5 & 154 & 9.1 & 177 & 18.7 & 176 & 18.5 \\
\hline Spain & 474 & 28.0 & 460 & 27.0 & 171 & 18.1 & 177 & 18.6 \\
\hline \multicolumn{9}{|c|}{ Parental education (ISCED levels) } \\
\hline Missing & 5 & 0.3 & 1 & 0.1 & 3 & 0.3 & 3 & 0.3 \\
\hline Low (levels 0-2) & 101 & 6.0 & 102 & 6.0 & 32 & 3.4 & 32 & 3.4 \\
\hline Medium (levels 3-5) & 770 & 45.5 & 742 & 43.6 & 402 & 42.5 & 416 & 43.7 \\
\hline High (levels 6-8) & 816 & 48.2 & 856 & 50.3 & 509 & 53.8 & 502 & 52.7 \\
\hline Age (years) & Mean & SD & Mean & SD & Mean & SD & Mean & SD \\
\hline Age at baseline & 6.1 & 1.8 & 6.3 & 1.7 & 5.9 & 1.8 & 6.1 & 1.8 \\
\hline Age at follow-up & 8.1 & 1.8 & 8.2 & 1.8 & 11.7 & 1.8 & 11.9 & 1.8 \\
\hline \multicolumn{9}{|l|}{ BMI percentile ${ }^{a}$} \\
\hline BMI (PCTL.) at baseline & 57.3 & 29.6 & 59.0 & 29.1 & 56.3 & 29.5 & 58.1 & 28.9 \\
\hline BMI (PCTL.) at follow-up & 60.2 & 30.0 & 60.3 & 29.9 & 64.5 & 28.5 & 62.2 & 29.0 \\
\hline \multicolumn{9}{|c|}{ Accelerometer wear time (min./day) } \\
\hline Wear time at baseline & 704.5 & 120.4 & 699.6 & 126.1 & 708.8 & 137.4 & 707.3 & 135.4 \\
\hline Wear time at follow-up & 695.8 & 110.1 & 698.5 & 109.5 & 754.9 & 114.5 & 757.3 & 101.3 \\
\hline \multicolumn{9}{|l|}{ MVPA (min./day) } \\
\hline MVPA at baseline & 55.5 & 22.5 & 47.6 & 19.9 & 53.4 & 22.9 & 46.2 & 19.3 \\
\hline MVPA at follow-up & 57.6 & 25.0 & 48.2 & 21.7 & 58.5 & 24.6 & 47.9 & 20.4 \\
\hline
\end{tabular}

Abbreviations: ISCED International Standard Classification of Education, BMI body mass index, MVPA moderate-to-vigorous physical activity

a Based on the (IOTF) BMI percentile curves updated by Cole \& Lobstein [29]

45 or 60 min in MVPA at baseline and 2-year follow-up, tend to have lower BMI percentiles at 2-year follow-up ( $\beta:-1.195,95 \%$ CI: $-2.712,0.323$ and $\beta:-1.266,95 \% \mathrm{CI}$ : $-2.957,0.425)$ than children who did never achieve the 45 or 60 min MVPA per day. During 6-year follow-up, children who did engage less than 45 or $60 \mathrm{~min}$ at baseline but became sufficiently active at follow-up $(\geq 45$ or $60 \mathrm{~min}$ per day), had negative $\beta$-coefficients of -3.390 (95\% CI: - 6.298,-0.482) and - 3.925 (95\% CI: - 6.512,1.338) for the 45-min and 60-min MVPA cutoff, respectively, compared to children who were insufficiently active at baseline and 6-year follow-up, respectively. The strongest association between MVPA on BMI percentiles at follow-up was found in children who engaged at least $45 \mathrm{~min}$ per day at baseline and 6-year follow-up ( $\beta$ : $-4.511,95 \%$ CI: $-7.273,-1.749$ ).
Analogously, the odds ratios for becoming overweight at 2-year and 6-year follow-up were calculated for the different MVPA cutoffs (30, 45 and $60 \mathrm{~min}$ per day). At both followups, the lowest odds for becoming overweight was observed in children who were sufficiently active at baseline and follow-up - regardless of the MVPA cutoff (Fig. 2).

Compared to children who were insufficiently active in both waves (ref.), the odds for becoming overweight at 2-year follow-up was $31 \%$ lower in children who were insufficiently active at baseline but became sufficiently active at follow-up for the 45-min MVPA cutoff as well as for the 60-min MVPA cutoff (Fig. 2). Even smaller odds ratios for becoming overweight at 2-year follow-up were found in children who were sufficiently active in both waves (45-min cutoff: $\mathrm{OR}=0.628 ; 60$ - $\mathrm{min}$ cutoff: $\mathrm{OR}=0.546)$. 
Table 2 Association between combinations of different MVPA levels at baseline and follow-up with BMI percentile at 2-year ( $N=$ 3393) and 6-year follow-up ( $N=1899)$

\begin{tabular}{|c|c|c|c|c|c|c|}
\hline \multirow{2}{*}{$\begin{array}{l}\text { Exposure: } \\
\text { MVPA } \\
\text { categories }^{c}\end{array}$} & \multicolumn{3}{|c|}{ BMI percentile at 2-year follow-up } & \multicolumn{3}{|c|}{ BMI percentile at 6-year follow-up } \\
\hline & $\begin{array}{l}\mathrm{N} \\
(\%)\end{array}$ & $\begin{array}{l}\beta^{\mathbf{b}} \\
(95 \% \mathrm{Cl})\end{array}$ & $\overline{p \text {-value }}$ & $\begin{array}{l}\mathrm{N} \\
(\%)\end{array}$ & $\begin{array}{l}\beta^{\mathrm{b}} \\
(95 \% \mathrm{Cl})\end{array}$ & $p$-value \\
\hline \multicolumn{7}{|c|}{$\begin{array}{l}\text { Cutoff: } 30 \text { min./day } \\
\text { (baseline / follow-up) }\end{array}$} \\
\hline Ref. - / - & $176(5.2 \%)$ & 0 & l & $65(3.4 \%)$ & 0 & l \\
\hline$-1+$ & $307(9.0 \%)$ & $0.229(-2.876 ; 3.335)$ & 0.879 & $241(12.7 \%)$ & $1.780(-4.179 ; 7.738)$ & 0.541 \\
\hline$+1-$ & $359(10.6 \%)$ & $1.288(-1.679 ; 4.256)$ & 0.377 & $195(10.3 \%)$ & $3.541(-2.533 ; 9.615)$ & 0.239 \\
\hline$+/+$ & $2551(75.2 \%)$ & $0.337(-2.252 ; 2.926)$ & 0.789 & $1398(73.6 \%)$ & $-0.265(-5.728 ; 5.197)$ & 0.921 \\
\hline \multicolumn{7}{|c|}{ Cutoff: 45 min./day (baseline / follow-up) } \\
\hline Ref. - / - & $828(24.4 \%)$ & 0 & / & $434(22.9 \%)$ & 0 & I \\
\hline$-1+$ & $652(19.2 \%)$ & $0.120(-1.614 ; 1.853)$ & 0.887 & $466(24.5 \%)$ & $-3.390(-6.298 ;-0.482)$ & 0.025 \\
\hline$+/-$ & $558(16.4 \%)$ & $0.114(-1.683 ; 1.912)$ & 0.896 & $319(16.8 \%)$ & $1.595(-1.572 ; 4.762)$ & 0.307 \\
\hline$+/+$ & $1355(40.0 \%)$ & $-1.195(-2.712 ; 0.323)$ & 0.117 & $680(35.8 \%)$ & $-4.511(-7.273 ;-1.749)$ & 0.003 \\
\hline \multicolumn{7}{|c|}{ Cutoff: 60 min./day (baseline / follow-up) } \\
\hline Ref. - / - & $1772(52.2 \%)$ & 0 & I & $987(52.0 \%)$ & 0 & I \\
\hline$-1+$ & $622(18.3 \%)$ & $-0.374(-1.914 ; 1.165)$ & 0.618 & $402(21.2 \%)$ & $-3.925(-6.512 ;-1.338)$ & 0.005 \\
\hline$+/-$ & $491(14.5 \%)$ & $-0.538(-2.229 ; 1.153)$ & 0.516 & $289(15.2 \%)$ & $-0.532(-3.431 ; 2.367)$ & 0.707 \\
\hline$+1+$ & $508(15.0 \%)$ & $-1.266(-2.957 ; 0.425)$ & 0.135 & $221(11.6 \%)$ & $-4.184(-7.461 ;-0.908)$ & 0.015 \\
\hline
\end{tabular}

Abbreviations: $B M I$ body mass index, MVPA moderate-to-vigorous physical activity, $\mathrm{Cl}$ confidence interval

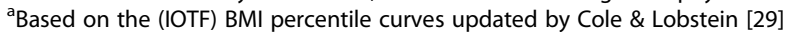

${ }^{b}$ Estimates were adjusted for age, sex, parental education, baseline BMI percentile, duration between baseline and follow-up survey, and country

${ }^{c}+:$ MVPA $\geq$ cutoff (minutes per day), -: MVPA < cutoff (minutes per day)

At the 6-year follow-up, the lowest odds for becoming overweight has been found in children who were sufficiently active at both waves with an OR of 0.545 (95\% CI: $0.382,0.779)$ for the 45-min MVPA cutoff and an OR of 0.393 (95\% CI: $0.242,0.638$ ) the 60 -min cutoff (as compared to children who did not achieve the 45 or 60 min MVPA per day, neither at baseline nor at followup). The odds for becoming overweight at 6-year followup in children who were insufficiently active at baseline but became sufficiently active at follow-up, was

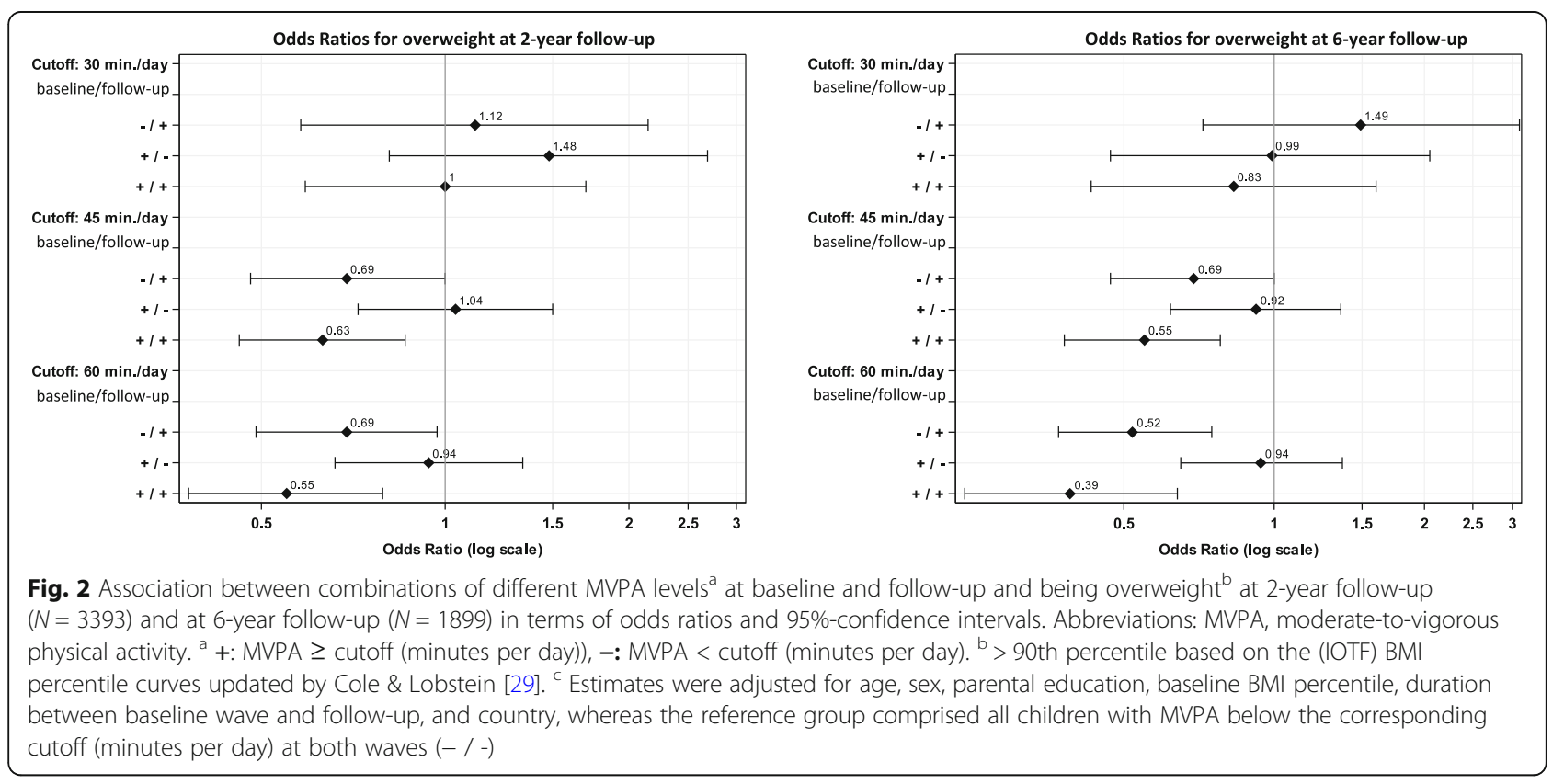


approximately $31 \%$ lower for the 45 -min MVPA cutoff (OR: 0.686, 95\% CI: 0.471, 0.999) and 48\% lower for the 60-min MVPA cutoff (OR: 0.524, 95\% CI: 0.365, 0.752), compared to children who were insufficiently active in both waves. Tables 3 and 4 in the Annex show all odds ratios and 95\% confidence intervals graphically presented in Fig. 2.

\section{Association between weight status and subsequent MVPA levels}

The longitudinal association between weight status and subsequent MVPA levels was analyzed using different combinations of weight status at baseline and 2-/6-year follow-up, respectively as exposure for the change in MVPA at 2-year and 6-year follow-up compared to the reference category (normal weight at both baseline and follow-up), see Table 5.

Most children remained categorized as either normal weight (2-year follow-up: 74\% (2512/3393); 6-year follow-up: $71 \%(1349 / 1899))$ or overweight (2-year follow-up: 16\% (545/3393); 6-year follow-up: 13\% (244/ 1899) during follow-ups. In contrast, only $2.6 \%$ (T1) and $4.6 \%$ (T3) changed from overweight to normal weight and $7.3 \%$ (T1) and $11.5 \%$ (T3) became overweight in the time between baseline and follow-ups. In particular, children who were normal weight at baseline but overweight at the 6-year follow-up, decreased their MVPA per day by on average $7.5 \mathrm{~min}(95 \% \mathrm{CI}$ : $-10.700,-4.323)$ on average compared to the reference category (normal weight at baseline and follow-up).

Analogously to the approach described above, odds ratios for being sufficiently active according to the three different MVPA cutoffs ( $\geq 30 / 45 / 60$ min per day) at 2year and 6-year follow-up were calculated for different weight trajectories at baseline and follow-up.

Regarding to the 30-min cutoff, the most notable result was that children who were overweight at both waves had a $27 \%$ decreased odds to even achieve $30 \mathrm{~min}$ MVPA per day at 2-year follow-up (Fig. 3). Regarding the aim to reach at least 45 or 60 min MVPA per day, the lowest odds was observed in both follow-ups for children who changed their weight status from normal weight (baseline) to overweight (follow-up) with ORs of 0.63 (2-year follow up) and 0.46 (6-year follow up) as compared to normal weight children, that did not change their weight status (Fig. 3). Moreover it was seen, that children who were overweight at baseline and 6year follow-up, respectively, had a 38\% decreased odds to be sufficiently active according the WHO recommendation of $60 \mathrm{~min}$ MVPA per day (OR: 0.624; 95\%-CI:

Table 3 Association between combinations of different MVPA levels at baseline and follow-up and being overweight at 2-year ( $N=3393)$ and 6-year follow up $(N=1899)$ in terms of prevalence of overweight, odds ratios and 95\%-confidence intervals

\begin{tabular}{|c|c|c|c|c|c|c|c|c|}
\hline \multirow{2}{*}{$\begin{array}{l}\text { Exposure: } \\
\text { MVPA } \\
\text { categories }^{a}\end{array}$} & \multicolumn{4}{|c|}{$\begin{array}{l}\text { Prevalence and odds ratios for becoming overweight at 2- } \\
\text { year follow-up }\end{array}$} & \multicolumn{4}{|c|}{$\begin{array}{l}\text { Prevalence and odds ratios for becoming overweight at 6- } \\
\text { year follow-up }\end{array}$} \\
\hline & $\bar{N}$ & $\%^{\mathrm{b}}$ & $O R^{c}$ & $95 \% \mathrm{Cl}$ & $\mathrm{N}$ & $\%^{b}$ & $\mathrm{OR}^{\mathrm{c}}$ & $95 \% \mathrm{Cl}$ \\
\hline \multicolumn{9}{|c|}{$\begin{array}{l}\text { Cutoff: } 30 \text { min./day } \\
\text { (baseline / follow-up) }\end{array}$} \\
\hline Ref. - / - & 176 & $32.4 \%$ & 0 & I & 65 & $33.8 \%$ & 0 & / \\
\hline$-/+$ & 307 & $19.5 \%$ & 1.119 & $0.582 ; 2.152$ & 241 & $31.5 \%$ & 1.492 & $0.718 ; 3.102$ \\
\hline$+/-$ & 359 & $39.0 \%$ & 1.479 & $0.814 ; 2.687$ & 195 & $29.2 \%$ & 0.986 & $0.474 ; 2.052$ \\
\hline$+1+$ & 2551 & $21.1 \%$ & 1.003 & $0.592 ; 1.698$ & 1398 & $22.0 \%$ & 0.829 & $0.430 ; 1.600$ \\
\hline \multicolumn{9}{|c|}{$\begin{array}{l}\text { Cutoff: } 45 \text { min./day } \\
\text { (baseline / follow-up) }\end{array}$} \\
\hline Ref. - / - & 828 & $31.6 \%$ & 0 & / & 434 & $32.7 \%$ & 0 & / \\
\hline$-1+$ & 652 & $18.6 \%$ & 0.692 & $0.477 ; 1.003$ & 466 & $23.2 \%$ & 0.686 & $0.471 ; 0.999$ \\
\hline$+1-$ & 558 & $28.0 \%$ & 1.043 & $0.724 ; 1.504$ & 319 & $27.0 \%$ & 0.915 & $0.617 ; 1.359$ \\
\hline$+1+$ & 1355 & $18.8 \%$ & 0.628 & $0.460 ; 0.859$ & 680 & $18.7 \%$ & 0.545 & $0.382 ; 0.779$ \\
\hline \multicolumn{9}{|c|}{$\begin{array}{l}\text { Cutoff: } 60 \text { min./day } \\
\text { (baseline / follow-up) }\end{array}$} \\
\hline Ref. - / - & 1772 & $27.4 \%$ & 0 & / & 987 & $29.9 \%$ & 0 & I \\
\hline$-1+$ & 622 & $19.0 \%$ & 0.694 & $0.496 ; 0.970$ & 402 & $16.9 \%$ & 0.524 & $0.365 ; 0.752$ \\
\hline$+1-$ & 491 & $22.4 \%$ & 0.936 & $0.655 ; 1.337$ & 289 & $24.2 \%$ & 0.941 & $0.647 ; 1.367$ \\
\hline$+1+$ & 508 & $15.9 \%$ & 0.546 & $0.378 ; 0.789$ & 221 & $13.6 \%$ & 0.393 & $0.242 ; 0.638$ \\
\hline
\end{tabular}

Abbreviations: MVPA moderate-to-vigorous physical activity, OR odds ratio, $\mathrm{Cl}$ confidence interval

${ }^{a}+$ : MVPA $\geq$ cutoff (minutes per day), -: MVPA < cutoff (minutes per day)

${ }^{b}>90$ th percentile based on the (IOTF) BMI percentile curves updated by Cole \& Lobstein [29]

'Estimates were adjusted for age, sex, parental education, baseline BMI percentile, duration between baseline and follow-up survey, and country 
Table 4 Association between combination of different weight status according to BMl percentiles at baseline and follow-up and sufficient engagement in MVPA according to different cutoffs at 2-year ( $N=3393)$ and 6-year follow-up $(N=1899)$ in terms of prevalences of children reaching at least the cutoffs, odds ratios, and 95\%-confidence intervals

\begin{tabular}{|c|c|c|c|c|c|c|c|c|c|c|}
\hline \multirow{3}{*}{$\begin{array}{l}\text { Exposure: } \\
\text { Weight categories } \\
\text { Baseline } \rightarrow \text { follow-up }\end{array}$} & \multicolumn{10}{|c|}{ Sufficient MVPA (min./day) at 2-year follow-up } \\
\hline & \multicolumn{4}{|c|}{ Cutoff: $\geq 30 \mathrm{~min}$} & \multicolumn{3}{|c|}{ Cutoff: $\geq 45 \mathrm{~min}$} & \multicolumn{3}{|c|}{ Cutoff: $\geq 60 \mathrm{~min}$} \\
\hline & $\mathrm{N}$ & $\%^{\mathrm{a}}$ & $O^{b}$ & $95 \% \mathrm{Cl}$ & $\%^{\mathrm{a}}$ & $O R^{b}$ & $95 \% \mathrm{Cl}$ & $\%^{a}$ & $O^{b}$ & $95 \% \mathrm{Cl}$ \\
\hline NW $\rightarrow$ NW (Ref.) & 2512 & $87.0 \%$ & 1 & / & $62.6 \%$ & 1 & / & $35.7 \%$ & 1 & / \\
\hline $\mathrm{NW} \rightarrow \mathrm{OW}$ & 249 & $81.9 \%$ & 0.826 & $0.566 ; 1.206$ & $46.2 \%$ & 0.532 & $0.398 ; 0.711$ & $25.3 \%$ & 0.634 & $0.460 ; 0.875$ \\
\hline $\mathrm{OW} \rightarrow \mathrm{NW}$ & 87 & $86.2 \%$ & 1.024 & $0.521 ; 2.010$ & $59.8 \%$ & 0.967 & $0.598 ; 1.564$ & $36.8 \%$ & 1.197 & $0.742 ; 1.930$ \\
\hline \multirow[t]{2}{*}{$\mathrm{OW} \rightarrow \mathrm{OW}$} & 545 & $71.9 \%$ & 0.728 & $0.560 ; 0.946$ & $47.5 \%$ & 0.864 & $0.695 ; 1.074$ & $25.0 \%$ & 0.857 & $0.676 ; 1.087$ \\
\hline & \multicolumn{10}{|c|}{ Sufficient MVPA (min./day) at 6-year follow-up } \\
\hline \multicolumn{2}{|l|}{$\begin{array}{l}\text { Exposure: } \\
\text { Weight categories }\end{array}$} & \multicolumn{3}{|c|}{ Cutoff: $\geq 30 \mathrm{~min}$} & \multicolumn{3}{|c|}{ Cutoff: $\geq 45 \mathrm{~min}$} & \multicolumn{3}{|c|}{ Cutoff: $\geq 60 \mathrm{~min}$} \\
\hline Baseline $\rightarrow$ follow-up & $\mathbf{N}$ & $\%^{\mathrm{a}}$ & $O R^{b}$ & $95 \% \mathrm{Cl}$ & $\%^{a}$ & $O R^{b}$ & $95 \% \mathrm{Cl}$ & $\%^{a}$ & $O R^{b}$ & $95 \% \mathrm{Cl}$ \\
\hline NW $\rightarrow$ NW (Ref.) & 1349 & $87.4 \%$ & 1 & / & $63.4 \%$ & 1 & / & $36.6 \%$ & 1 & / \\
\hline $\mathrm{NW} \rightarrow \mathrm{OW}$ & 219 & $84.9 \%$ & 0.793 & $0.510 ; 1.234$ & $53.0 \%$ & 0.588 & $0.429 ; 0.806$ & $22.8 \%$ & 0.459 & $0.322 ; 0.655$ \\
\hline$W \rightarrow N W$ & 87 & $87.4 \%$ & 1.618 & $0.789 ; 3.318$ & $63.2 \%$ & 1.373 & $0.834 ; 2.262$ & $35.6 \%$ & 1.226 & $0.746 ; 2.015$ \\
\hline $\mathrm{OW} \rightarrow \mathrm{OW}$ & 244 & $81.1 \%$ & 1.252 & $0.826 ; 1.899$ & $48.8 \%$ & 0.870 & $0.636 ; 1.190$ & $19.7 \%$ & 0.624 & $0.434 ; 0.896$ \\
\hline
\end{tabular}

Abbreviations: BMI body mass index, MVPA moderate-to-vigorous physical activity, OR odds ratio, $C l$ confidence interval, OW overweight children (>90th percentile of $\mathrm{BMI}$ ), NW normal weight children ( $\leq 90$ th percentile of BMI) based on the (IOTF) BMI percentile curves updated by Cole \& Lobstein [29]

${ }^{\text {a }}$ Prevalence of children reaching at least the corresponding cutoff

bEstimates were adjusted for age, sex, education, baseline MVPA, duration (years) between baseline and follow-up survey, and country

$0.434,0.896)$, compared to the reference category of children of normal weight at both baseline and 6-year follow-up (Fig. 3).

\section{Sensitivity analyses}

As different markers for weight status have been used in studies investigating associations between PA and overweight, we also ran our analyses with percentiles of waist circumference. We found only small discrepancies in terms of smaller/wider confidence intervals, but neither did the direction of association change nor did appear or disappear. Moreover, we did not reveal notable differences either regarding different regions (North vs. South), or for boys and girls.

\section{Discussion}

The present study aimed to investigate the bi-directional association between objectively measured MVPA and weight status in a large sample, and to analyze whether less than 60 min MVPA per day may also prevent childhood overweight. To the best of our knowledge, until now, a solid data base (i.e. reliable measurements in a large longitudinal sample of children) for analyzing the association of changes in PA levels and weight status

Table 5 Association between the combinations of different weight status according BMI percentiles at baseline and follow-up with average duration of MVPA per day at 2-year $(N=3393)$ and 6-year follow-up $(N=1899)$

\begin{tabular}{|c|c|c|c|c|c|c|}
\hline \multirow{2}{*}{$\begin{array}{l}\text { Exposure: } \\
\text { Weight } \\
\text { categories } \\
\text { (baseline } \rightarrow \\
\text { follow-up) }\end{array}$} & \multicolumn{3}{|c|}{$\begin{array}{l}\text { MVPA (min./day) } \\
\text { at 2-year follow-up }\end{array}$} & \multicolumn{3}{|c|}{$\begin{array}{l}\text { MVPA (min./day) } \\
\text { at 6-year follow-up }\end{array}$} \\
\hline & $\begin{array}{l}\mathrm{N} \\
(\%)\end{array}$ & $\begin{array}{l}\beta^{a} \\
(95 \% \mathrm{Cl})\end{array}$ & $p$-value & $\bar{N}$ & $\begin{array}{l}\beta^{a} \\
(95 \% \mathrm{Cl})\end{array}$ & $p$-value \\
\hline NW $\rightarrow$ NW (Ref.) & $\begin{array}{l}2512 \\
(74.0 \%)\end{array}$ & 0 & / & $\begin{array}{l}1349 \\
(71.0 \%)\end{array}$ & 0 & / \\
\hline $\mathrm{NW} \rightarrow \mathrm{OW}$ & $\begin{array}{l}249 \\
(7.3 \%)\end{array}$ & $-4.612(-7.548 ;-1.676)$ & 0.004 & $\begin{array}{l}219 \\
(11.5 \%)\end{array}$ & $-7.512(-10.700 ;-4.323)$ & $<.001$ \\
\hline $\mathrm{OW} \rightarrow \mathrm{NW}$ & $87(2.6 \%)$ & $0.917(-3.887 ; 5.721)$ & 0.696 & $87(4.6 \%)$ & $1.790(-3.055 ; 6.635)$ & 0.450 \\
\hline $\mathrm{OW} \rightarrow \mathrm{OW}$ & $545(16.1 \%)$ & $-2.103(-4.297 ; 0.091)$ & 0.059 & $244(12.8 \%)$ & $-3.657(-6.838 ;-0.475)$ & 0.026 \\
\hline
\end{tabular}

Abbreviations: BMI body mass index, MVPA moderate-to-vigorous physical activity, $\mathrm{Cl}$ confidence interval, OW overweight children (>90th percentile of BMI), NW normal weight children ( $\leq 90$ th percentile of BMI) based on the (IOTF) BMI percentile curves updated by Cole \& Lobstein [29]

${ }^{\mathrm{a}}$ Estimates were adjusted for age, sex, parental education, baseline MVPA, duration between baseline and follow-up survey, and country 


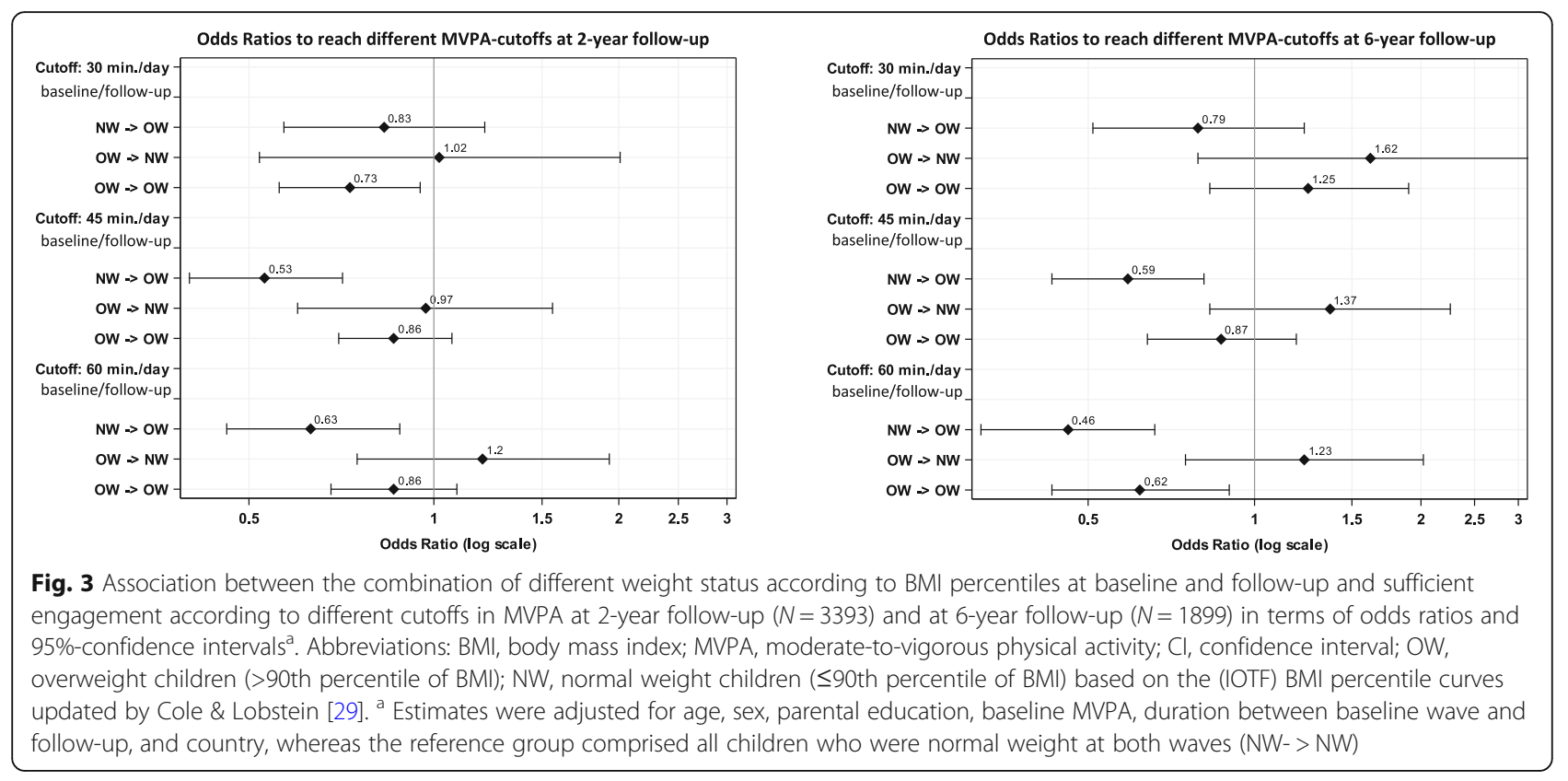

(and vice versa) was missing. Regarding the first aim, our results showed that children being sufficiently active at baseline and follow-up reduced the odds of becoming overweight at follow-up and that being overweight was associated with a lower odds of achieving the generally recommended MVPA levels in the following years of childhood. In particular, our data showed that the MVPA cutoff recommended by the WHO (at least 60 min per day) is evident regarding the prevention of childhood overweight. However, concerning the second aim, we found a comparable protective effect even for a threshold of 45 min daily MVPA. Therefore, future studies promoting MVPA should target to motivate children to engage in more MVPA as before. To optimally prevent excess weight gain, 60 min MVPA per day are still recommended. Whilst the latter might be hard to achieve, particularly for overweight children, those children should be motivated to engage at least $45 \mathrm{~min}$ in MVPA - without losing the preventive effect.

We further found that only a small proportion of children who were overweight at baseline became normal weight during the following 2 or 6 years (2.6 and 4.6\%, respectively). In contrast, more normal weight children at baseline were overweight at follow-up (2-year followup: 7.3\%, 6-year follow-up: $11.5 \%$, Table 5). Thus, once overweight was established, it was harder to reverse this development since high MVPA levels shown to be preventive for overweight were hard to achieve for overweight children. In summary, the observed bi-directional association between MVPA and BMI highlight a vicious circle regarding excess weight gain. On a positive note, the number of children who were insufficiently active at baseline but became sufficiently active at both follow- ups was higher than the number of children who were active enough at baseline but insufficiently active at follow-up, regardless whether the MVPA cutoff was 45 or 60 min per day.

We carried out several sensitivity analyses to evaluate whether the results may be influenced e.g. by the definition of weight status, or to check for robustness of results by stratifying the data by sex or region (since recent studies reported that children from Northern Europe were more likely to achieve the recommended MVPA level [60 min MVPA per day] compared to children living in Southern Europe [32]). However, none of these approaches yielded significant results that differed from the central findings of this study.

\section{Comparing the present findings with other studies}

Comparing our results was challenging since, to our knowledge, no study analyzed bi-directional associations between objectively measured MVPA and BMI in such a large international sample so far. Despite the large data base, cross-country comparisons were not possible due to loss of observations in each country. In general, our results were in line with the consistent findings of recent studies which found that PA levels were lower in children with overweight compared to normal weight children and that boys accumulate more MVPA than girls (Table 1) [17, 33, 34].

Although a growing number of longitudinal studies on obesity used objective PA measures in recent years [15, 16, 18, 33, 35-38], results were inconsistent regarding the association between PA and weight status. One study investigated the bi-directional association between PA and weight status and reported no association in school- 
aged children [35]. Another longitudinal study did not observe any association between baseline PA and the change in body fat percentage at follow-up but a statistically significant relationship between baseline body fat and PA at follow-up ( $r=-0.16$ to -0.22$)$ [15]. In a further study, neither MVPA nor sedentary behavior predicted a higher waist circumference at follow-up, but higher baseline waist circumference was associated with increased sedentary behavior at follow-up [39]. NorthEast England, a 2-year follow-up study showed that the decline in MVPA was associated with greater increases of fat mass index and BMI z-scores in 7-year-old boys, but not in girls of the same age [36]. The authors hypothesized that PA may have a higher impact on overweight in boys than in girls. In the USA, a 6-year followup study reported that MVPA at the age of 9 years was negatively associated with BMI at the age of 15 years in boys and girls having overweight (90th BMI percentile). In the same study, increased sedentary behavior was associated with increases of BMI 6 years later, independent of the amount of MVPA. The authors concluded that decreasing sedentary behavior and increasing MVPA may have independent beneficial effects on the prevalence of overweight [37]. In contrast, another study from the USA reported that the association between sedentary behavior and BMI z-score in preschool children disappeared after adjustment for MVPA [38]. A 5-year follow-up study $(N=600)$ also conducted at three different time points and in five European countries (Germany, Italy, Poland, Belgium, and Spain) found a bidirectional association between PA and weight status in 430 children having at least two measurements of objectively measured PA and BMI [40]. This seems particularly interesting, since the study used another device and different sampling intervals to measure PA (Sensewear Armband with an epoch of $60 \mathrm{~s}$ ), but, however, their results also suggest a bi-directional relationship between weight status and PA. The authors particularly highlighted the role of sedentary behavior regarding childhood obesity, since they found the positive association between sedentary behavior and BMI to increase with age. Contrary to our study, PA was included without considering current PA guidelines and hence, results are therefore not directly comparable with ours.

\section{Strengths and limitations}

One important strength of the present study is the large sample size (2-year follow-up $N=3393$; 6-year follow-up $N=1899)$ used to investigate the association between different trajectories of MVPA levels and different trajectories of weight status. Furthermore, we provide specific dose-response relationships of different MVPA cutoffs facilitating the recommendation of specific MVPA levels for the prevention of childhood overweight. Regarding
PA, the used accelerometers are commonly used to quantify the amount and intensity of PA [41] and the applied cutoff points by Evenson and colleagues are recommended for young children [26]. Further, to account for times when children took off the device during sports activities we improved accelerometer data by imputing MVPA (if applicable) as recommended [25]. To accurately assess the sporadic PA pattern in children, accelerometer sampling intervals shorter than five seconds are recommended [42]. Thus, the applied sampling intervals ( 15 to $60 \mathrm{~s}$ ) used in this study is a limitation we need to acknowledge. At least, to account for the wellknown underestimation associated with the use of PA data based on longer epoch settings [43], we used the correction factor recommended by Colley and colleagues [23] for the epoch setting of $60 \mathrm{~s}$ selected in most cases in Italy during the first wave.

However, our study has a clear limitation - the attrition of the study sample is a common problem of longitudinal studies [33]. Similar to our observation, other studies reported a high attrition during the 6-year follow-up period, leading to a downsized study population of about one third [33, 37]. There are also limitations regarding the PA assessment in this study. Although a minimum accelerometer wear time of four to five days [9] and ten hours have recently been recommended [37, 44], three days and six hours have been reported to provide acceptable reliability of total PA, MVPA, and total sedentary time [45]. Another limitation is the use of different Actigraph accelerometers, since inconclusive findings have been found in validation studies. Whereas some study reported that different Actigraph devices provided comparable measured counts across all PA intensities [46, 47], one study highlighted differences between Actigraph models particular for lower intensities such as light PA and sedentary time [48]. However, light PA and sedentary time have not been addressed in the present study, since this would have gone beyond the scope of the present study. Finally, with regard to representativeness of the data base it must be stressed that our study did not intended to be strictly nationally representative. Nevertheless, the study provides population-based samples that were drawn from communities considered to be typical of their geographical region.

\section{Conclusion}

An inverse, bi-directional association between objectively measured MVPA levels and BMI in children was observed for the generally recommended 60 min MVPA per day, but also for an even lower MVPA cutoff of 45 min. While sufficient MVPA (45 or 60 min per day) prevent overweight in later childhood, such high MVPA levels are hard to achieve by children having overweight. 
This highlights a vicious circle that should be considered in primary prevention of childhood overweight and obesity. In summary, at least $60 \mathrm{~min}$ MVPA are still recommended for the prevention of childhood overweight, but, if that is not possible, 45 min might also be sufficient. However, more high-quality studies, i.e., longitudinal studies with objectively and standardized measurements of weight status and PA, are needed to support our findings.

\section{Acknowledgements}

We would like to thank the children and their parents (or caregivers) for their participation in the IDEFICS/I.Family study.

\section{Authors' contributions}

O.S., H.P and W.A. were major contributors in writing the manuscript. They conceptualized and designed the study and analyzed and interpreted the data. K. B, C.B., F.L., V.V., G.E., K.K., D.M., L.M., Y.P., A.P., L.R. and M.T. contributed to coordination and data collection. All authors read and improved the manuscript and approved the final manuscript.

\section{Funding}

This study as part of the IDEFICS and I. Family studies was financially supported by the European Commission within the Sixth RTD Framework Programme Contract No.016181 (FOOD) and the Seventh RTD Framework Programme Contract No.266044, respectively. The funding body was not involved in the study design, data collection, analysis and interpretation as well as manuscript writing. Open Access funding enabled and organized by Projekt DEAL.

\section{Availability of data and materials}

The datasets generated and analyzed during the current study are not publicly available because this study is based on highly sensitive data collected in young children. But interested researchers can contact the IDEF ICS and I. Family consortia (http://www.ideficsstudy.eu/ldefics/ and http:// www.ffamilystudy.eu/) to discuss possibilities for data access.

\section{Declarations}

\section{Ethics approval and consent to participate}

All parents and their children above 12 years old signed informed consent, while younger children gave oral consent prior to the examinations in addition to the signed parental consent. Ethical approval was obtained from the ethics committees for all participating centres in each country: Ethics Committee, University Hospital, Gent, Belgium; Cyprus National Bioethics Committee, Nicosia, Cyprus; Tallinn Medical Research Ethics Committee, Tallinn, Estonia; Ethics Committee of the University of Bremen, Bremen, Germany; Egészségügyi Tudományos Tanács, Pécs, Hungary; Azienda Sanitaria Locale Avellino Comitato Etico, Avellino, Italy; Regionala Etikprövningsnämnden i Göteborg, Gothenburg, Sweden; Comité Ético de Investigación Clínica de Aragón, Zaragoza, Spain.

\section{Consent for publication}

Not applicable.

\section{Competing interests}

The authors declare that they have no competing interests.

\section{Author details}

'Department of Epidemiological Methods and Etiological Research, Leibniz Institute for Prevention Research and Epidemiology - BIPS, Achterstr. 30, D-28359 Bremen, Germany. ${ }^{2}$ Department of Biometry and Data Management, Leibniz Institute for Prevention Research and Epidemiology BIPS, Achterstraße 30, D-28359 Bremen, Germany. ${ }^{3}$ Working group Epidemiology of Demographic Change, Institute for Public Health and Nursing Sciences (IPP), University of Bremen, Bremen, Germany. ${ }^{4}$ Institute of Food Sciences, National Research Council of Italy, Avellino, Italy. ${ }^{5}$ Department of Rehabilitation Sciences, Faculty of Medicine and Health Sciences, Ghent University, Ghent, Belgium. ${ }^{6}$ Department of Public Health, School of Health
Sciences, University of Skövde, Skövde, Sweden. 'Department of Chronic Diseases, National Institute for Health Development, Tallinn, Estonia. ${ }^{8}$ School of Natural Sciences and Health, Tallinn University, Tallinn, Estonia. ${ }^{9}$ Institute of Psychology, University of Tartu, Tartu, Estonia. ${ }^{10}$ Department of Paediatrics, University of Pécs, Pécs, Hungary. ${ }^{11}$ GENUD (Growth, Exercise, Nutrition and Development) Research Group, Faculty of Health Sciences, University of Zaragoza, Edificio del SAl, C/Pedro Cerbuna s/n, 50009 Zaragoza, Spain. ${ }^{12}$ Instituto Agroalimentario de Aragón (IA2), Zaragoza, Spain. ${ }^{13}$ Instituto de Investigación Sanitaria Aragón (IIS Aragón), Zaragoza, Spain. ${ }^{14}$ Centro de Investigación Biomédica en Red de Fisiopatología de la Obesidad y Nutrición (CIBERObn), Madrid, Spain. ${ }^{15}$ Collaborating Centre of Sports Medicine, University of Brighton, Welkin House, Eastbourne, UK. ${ }^{16}$ Centre for Exercise, Nutrition and Health Sciences, School of Policy Studies, University of Bristol, Bristol BS8 1TZ, UK. ${ }^{17} \mathrm{NIHR}$ Bristol Biomedical Research Centre, University Hospitals Bristol NHS Foundation Trust and University of Bristol, Bristol, UK.

${ }^{18}$ Copenhagen Business School, Copenhagen, Denmark. ${ }^{19}$ Research and Education Institute of Child Health, Strovolos, Cyprus. ${ }^{20}$ Institute of Statistics, Faculty of Mathematics and Computer Science, University Bremen, Bremen, Germany.

Received: 16 November 2020 Accepted: 2 July 2021

Published online: 09 August 2021

\section{References}

1. Ogden $\mathrm{CL}$, Carroll MD, Kit BK, Flegal KM. Prevalence of childhood and adult obesity in the United States, 2011-2012. JAMA. 2014;311(8):806-14. https:// doi.org/10.1001/jama.2014.732.

2. Ahrens W, Pigeot I, Pohlabeln H, De Henauw S, Lissner L, Molnar D, et al. Prevalence of overweight and obesity in European children below the age of 10. Int J Obes. 2014;38(Suppl 2):S99-107. https://doi.org/10.1038/ijo.2 014.140.

3. Garrido-Miguel M, Oliveira A, Cavero-Redondo I, Alvarez-Bueno C, PozueloCarrascosa DP, Soriano-Cano A, et al. Prevalence of Overweight and Obesity among European Preschool Children: A Systematic Review and MetaRegression by Food Group Consumption. Nutrients. 2019;11(7). https://doi. org/10.3390/nu11071698.

4. Olds T, Maher C, Zumin S, Peneau S, Lioret S, Castetbon K, et al. Evidence that the prevalence of childhood overweight is plateauing: data from nine countries. Int J Pediatr Obes. 2011;6(5-6):342-60. https://doi.org/10.3109/174 77166.2011 .605895$.

5. Skinner AC, Perrin EM, Moss LA, Skelton JA. Cardiometabolic risks and severity of obesity in children and young adults. N Engl J Med. 2015;373(14): 1307-17. https://doi.org/10.1056/NEJMoa1502821.

6. Chung ST, Onuzuruike AU, Magge SN. Cardiometabolic risk in obese children. Ann N Y Acad Sci. 2018;1411(1):166-83. https://doi.org/10.1111/nya s.13602.

7. Rey-Lopez JP, Vicente-Rodriguez G, Biosca M, Moreno LA. Sedentary behaviour and obesity development in children and adolescents. Nutr Metab Cardiovasc Dis. 2008;18(3):242-51. https://doi.org/10.1016/.numecd.2 007.07.008.

8. Rauner A, Mess F, Woll A. The relationship between physical activity, physical fitness and overweight in adolescents: a systematic review of studies published in or after 2000. BMC Pediatr. 2013;13(19). https://doi. org/10.1186/1471-2431-13-19.

9. Ruiz JR, Rizzo NS, Hurtig-Wennlöf A, Ortega FB, Wärnberg J, Sjöström M. Relations of total physical activity and intensity to fitness and fatness. Am J Clin Nutr. 2006;84(2):299-303. https://doi.org/10.1093/ajcn/84.2.299.

10. Burgi F, Meyer U, Granacher U, Schindler C, Marques-Vidal P, Kriemler S, et al. Relationship of physical activity with motor skills, aerobic fitness and body fat in preschool children: a cross-sectional and longitudinal study (Ballabeina). Int J Obes. 2011;35(7):937-44. https://doi.org/10.1038/ijo.2011.54.

11. Jimenez-Pavon D, Kelly J, Reilly JJ. Associations between objectively measured habitual physical activity and adiposity in children and adolescents: systematic review. Int Pediatr Obes. 2010;5(1):3-18. https://doi. org/10.3109/17477160903067601.

12. Leech RM, McNaughton SA, Timperio A. The clustering of diet, physical activity and sedentary behavior in children and adolescents a review. Int J Behav Nutr Phys Act. 2014;11(4). https://doi.org/10.1186/1479-5868-11-4.

13. Bull FC, Al-Ansari SS, Biddle S, Borodulin K, Buman MP, Cardon G, et al. World Health Organization 2020 guidelines on physical activity and 
sedentary behaviour. Br J Sports Med. 2020;54(24):1451-62. https://doi.org/1 0.1136/bjsports-2020-102955.

14. CDC. Centers for Disease Control and Prevention. School Health Guidelines to Promote Healthy Eating and Physical Activity. 2011;60(5):1-80. https:/ www.cdc.gov/mmwr/pdf/rr/rr6005.pdf.

15. Metcalf BS, Hosking J, Jeffery AN, Voss LD, Henley W, Wilkin TJ. Fatness leads to inactivity, but inactivity does not lead to fatness: a longitudinal study in children (EarlyBird 45). Arch Dis Child. 2010;96(10):942-7. https://doi.org/1 0.1136/adc.2009.175927.

16. Ekelund U, Hildebrand M, Collings PJ. Physical activity, sedentary time and adiposity during the first two decades of life. Proc Nutr Soc. 2014;73(2):31929. https://doi.org/10.1017/S0029665114000019.

17. Cooper AR, Goodman A, Page AS, Sherar LB, Esliger DW, van Sluijs EM, et al. Objectively measured physical activity and sedentary time in youth: the International children's accelerometry database (ICAD). Int J Behav Nutr Phys Act. 2015;12(1):113. https://doi.org/10.1186/s12966-0150274-5.

18. Metcalf BS, Voss LD, Hosking J, Jeffery AN, Wilkin TJ. Physical activity at the government-recommended level and obesity-related health outcomes: a longitudinal study (early bird 37). Arch Dis Child. 2008;93(9):772-7. https:// doi.org/10.1136/adc.2007.135012.

19. Miguel-Berges ML, Reilly JJ, Moreno Aznar LA, Jimenez-Pavon D. Associations between pedometer-determined physical activity and adiposity in children and adolescents: systematic review. Clin J Sport Med. 2018;28(1): 64-75. https://doi.org/10.1097/JSM.0000000000000419.

20. Warburton DER, Bredin SSD. Lost in translation: what does the physical activity and health evidence actually tell us? In: Zibadi S, Watson RR, editors. Lifestyle in heart health and disease. San Diego: Elsevier; 2018. p. 175-86.

21. Ahrens W, Bammann K, Siani A, Buchecker K, De Henauw S, lacoviello L, et al. The IDEFICS cohort: design, characteristics and participation in the baseline survey. Int J Obes. 2011;35(Suppl 1):S3-15. https://doi.org/10.1038/ ijo.2011.30.

22. Bammann K, Lissner L, Pigeot I, Ahrens W. Instruments for health surveys in children and adolescents. Heidelberg: Springer International Publishing; 2019. https://doi.org/10.1007/978-3-319-98857-3.

23. Colley RC, Harvey A, Grattan KP, Adamo KB. Impact of accelerometer epoch length on physical activity and sedentary behaviour outcomes for preschool-aged children. Statistics Canada Health Rep. 2014;25(1):3-9.

24. Ridley K, Ainsworth BE, Olds TS. Development of a compendium of energy expenditures for youth. Int J Behav Nutr Phys Act. 2008;5(1):45. https://doi. org/10.1186/1479-5868-5-45.

25. De Meester F, De Bourdeaudhuij I, Deforche B, Ottevaere C, Cardon G. Measuring physical activity using accelerometry in 13-15-year-old adolescents: the importance of including non-wear activities. Public Health Nutr. 2011;14(12):2124-33. https://doi.org/10.1017/S1368980011001868.

26. Evenson KR, Catellier DJ, Gill K, Ondrak KS, McMurray RG. Calibration of two objective measures of physical activity for children. J Sports Sci. 2008;26(14): 1557-65. https://doi.org/10.1080/02640410802334196.

27. Choi L, Liu Z, Matthews CE, Buchowski MS. Validation of accelerometer wear and nonwear time classification algorithm. Med Sci Sports Exerc. 2011;43(2): 357-64. https://doi.org/10.1249/MSS.0b013e3181ed61a3.

28. Stomfai S, Ahrens W, Bammann K, Kovacs E, Marild S, Michels N, et al. Intraand inter-observer reliability in anthropometric measurements in children. Int J Obes. 2011;35(Suppl 1):S45-51. https://doi.org/10.1038/ijo.2011.34.

29. Cole TJ, Lobstein T. Extended international (IOTF) body mass index cut-offs for thinness, overweight and obesity. Pediatr Obes. 2012;7(4):284-94. https:// doi.org/10.1111/j.2047-6310.2012.00064.x.

30. UNESCO. International standard classification of education ISCED 2011 Montreal: UNESCO; 2012

31. Nagy P, Kovacs E, Moreno LA, Veidebaum T, Tornaritis M, Kourides $Y$, et al. Percentile reference values for anthropometric body composition indices in European children from the IDEFICS study. Int J Obes. 2014;38(Suppl 2):S1525. https://doi.org/10.1038/ijo.2014.131.

32. Konstabel K, Veidebaum T, Verbestel V, Moreno LA, Bammann K, Tornaritis $M$, et al. Objectively measured physical activity in European children: the IDEFICS study. Int J Obes. 2014;38(Suppl 2):S135-43. https://doi.org/10.1038/ ijo.2014.144.

33. Mitchell JA, Pate RR, Espana-Romero V, O'Neill JR, Dowda M, Nader PR. Moderate-to-vigorous physical activity is associated with decreases in body mass index from ages 9 to 15 years. Obesity. 2013;21(3):E280-93. https://doi. org/10.1002/oby.20118
34. Corder K, Sharp SJ, Atkin AJ, Griffin SJ, Jones AP, Ekelund U, et al. Change in objectively measured physical activity during the transition to adolescence. Br J Sports Med. 2015:49:730-6.

35. Hallal PC, Andersen LB, Bull FC, Guthold R, Haskell W, Ekelund U. Global physical activity levels: surveillance progress, pitfalls, and prospects. Lancet. 2012;380(9838):247-57. https://doi.org/10.1016/S0140-6736(12)60646-1.

36. Basterfield L, Pearce MS, Adamson AJ, Frary JK, Parkinson KN, Wright CM et al. Physical activity, sedentary behavior, and adiposity in English children. Am J Prev Med. 2012;42(5):445-51. https://doi.org/10.1016/j.amepre.2012.01. 007.

37. Mitchell JA, Pate RR, Beets MW, Nader PR. Time spent in sedentary behavior and changes in childhood BMI: a longitudinal study from ages 9 to 15 years. Int J Obes. 2013;37(1):54-60. https://doi.org/10.1038/ijo.2012.41.

38. Byun W, Liu J, Pate RR. Association between objectively measured sedentary behavior and body mass index in preschool children. Int J Obes. 2013;37(7): 961-5. https://doi.org/10.1038/ijo.2012.222.

39. Ekelund U, Luan J, Sherar LB, Esliger DW, Griew P, Cooper A, et al. Moderate to vigorous physical activity and sedentary time and cardiometabolic risk factors in children and adolescents. JAMA. 2012;307(7):704-12. https://doi. org/10.1001/jama.2012.156.

40. Schwarzfischer P, Gruszfeld D, Socha P, Luque V, Closa-Monasterolo R, Rousseaux D, et al. Longitudinal analysis of physical activity, sedentary behaviour and anthropometric measures from ages 6 to 11 years. Int J Behav Nutr Phys Act. 2018:15(1). https://doi.org/10.1186/s12966-018-0756-3.

41. Kolle E, Steene-Johannessen J, Klasson-Heggebo L, Andersen LB, Anderssen SA. A 5-yr change in Norwegian 9-yr-olds' objectively assessed physical activity level. Med Sci Sports Exerc. 2009;41(7):1368-73. https://doi.org/1 0.1249/MSS.0b013e31819a5e65

42. Guinhouya BC, Samouda H, de Beaufort C. Level of physical activity among children and adolescents in Europe: a review of physical activity assessed objectively by accelerometry. Public Health. 2013;127(4):301-11. https://doi. org/10.1016/.ppuhe.2013.01.020

43. Ojiambo R, Cuthill R, Budd H, Konstabel K, Casajus JA, Gonzalez-Aguero A, et al. Impact of methodological decisions on accelerometer outcome variables in young children. Int J Obes. 2011;35(Suppl 1):S98-103. https:// doi.org/10.1038/ijo.2011.40

44. Cain KL, Sallis JF, Conway TL, Van Dyck D, Calhoon L. Using accelerometers in youth physical activity studies: a review of methods. J Phys Act Health. 2013;10(3):437-50. https://doi.org/10.1123/jpah.10.3.437.

45. Basterfield L, Adamson AJ, Pearce MS, Reilly JJ. Stability of habitual physical activity and sedentary behavior monitoring by accelerometry in 6- to 8year-olds. J Phys Act Health. 2011;8(4):543-7. https://doi.org/10.1123/jpah. 8.4.543.

46. Sasaki JE, John D, Freedson PS. Validation and comparison of ActiGraph activity monitors. J Sci Med Sport. 2011;14(5):411-6. https://doi.org/10.1016/ j.jsams.2011.04.003.

47. Vanhelst J, Mikulovic J, Bui-Xuan G, Dieu O, Blondeau T, Fardy P, et al. Comparison of two ActiGraph accelerometer generations in the assessment of physical activity in free living conditions. BMC Res Notes. 2012;5(1):187. https://doi.org/10.1186/1756-0500-5-187.

48. Lee KY, Macfarlane DJ, Cerin E. Comparison of three models of actigraph accelerometers during free living and controlled laboratory conditions. Eur J Sport Sci. 2013;13(3):332-9. https://doi.org/10.1080/17461391.2011.643925.

\section{Publisher's Note}

Springer Nature remains neutral with regard to jurisdictional claims in published maps and institutional affiliations.

Ready to submit your research? Choose BMC and benefit from:

- fast, convenient online submission

- thorough peer review by experienced researchers in your field

- rapid publication on acceptance

- support for research data, including large and complex data types

- gold Open Access which fosters wider collaboration and increased citations

- maximum visibility for your research: over $100 \mathrm{M}$ website views per year

At $\mathrm{BMC}$, research is always in progress.

Learn more biomedcentral.com/submissions 